\title{
A touch of post-truth: the roles of narratives in urban policy mobilities
}

\author{
Thomas Honeck $^{1,2}$ \\ ${ }^{1}$ Leibniz Institute for Research on Society and Space, Erkner, Germany \\ ${ }^{2}$ Geography Department, Humboldt University of Berlin, Berlin, Germany \\ Correspondence: Thomas Honeck (thomas.honeck@leibniz-irs.de)
}

Received: 3 April 2017 - Revised: 16 January 2018 - Accepted: 17 January 2018 - Published: 4 April 2018

\begin{abstract}
This paper characterizes different types of policy narratives that influence the trans-local motion of urban policies and elaborates on their relations. The paper first introduces conceptual and methodological recommendations from policy narrative literature to debates on policy mobility. In an empirical section, it then analyzes narratives that support policies on temporary use of vacant lands and buildings in the German cities of Berlin and Stuttgart. Based on semi-structured interviews with experts and document reviews, the paper finds different, partly competing narratives on temporary use in both case study cities. It identifies their typical elements, categorising them by form and content. Referential narratives are understood as connecters between different cities and influencers of policy mobility. Finally, the paper shows how narratives work with association as well as imagination and thus emphasize the non-factual, yet inherent aspects of relational policy making.
\end{abstract}

\section{Introduction}

The term "post-truth" has become popular for "relating to or denoting circumstances in which objective facts are less influential in shaping public opinion than appeals to emotion and personal belief" (Oxford Dictionary, 2016). Indeed, the formation and impact of what Foucault (1981) discussed as the "discourse of truth" seems to reach another peak of public interest in recent years. Despite the new and prominent label "post-truth", the phenomenon itself is certainly not new and scholars have researched it from many perspectives. Of these, the narrative approach intends to grasp the social construction of a shared truth that becomes relevant for the political. "In public policy discourse, policy arguments are backed by narrative stories, which purport to explain how the world works" (Miller, 2012:43). As such, narratives have been characterized as inherent to policy making on different administrative scales, including the city level (Shanahan et al., 2017; Jones et al., 2014; Miller, 2012; Fischer, 2003).

In debates on urban policy mobilities, the notion of narrative has frequently been employed to discuss how policies are communicated as worthy of imitation and, thus, are applied between different urban contexts (Peck and Theodore, 2015; Healey, 2013; McCann, 2013; Gonzáles, 2011; McCann and
Ward, 2011). It is assumed that definitions of truth regarding the best available policy solutions are linked to shared narratives on cities, their relations, and policies (McCann, 2008). Such narratives allow "policies [to]become transportable, that something embedded in one place - with all the legal, institutional, historical, and administrative specificity that that entails - can travel elsewhere" (Rodgers, 2014:308). Urban planners and policy makers exchange experiences and knowledge through narratives (Healey, 2011). Typically, these narratives portray cities and projects as role models for distinctive urban policies (Peck and Theodore, 2015; Gonzáles, 2011; Temenos and McCann, 2012). Likewise, actors employ and manipulate narratives strategically to "boost" policies (e.g. McCann, 2013). Often such "policy narratives can be representationally inaccurate - and recognizably so - but still persist, indeed thrive" (Roe, 1994:51).

To this end, narratives shed light on the non-factual and non-rational, yet inherent aspects of territorial and relational urban policy making. These facets are particularly difficult to encompass, and even though the term narrative has frequently appeared in policy mobility literature, narrative's inner logic and especially the interplay of different narratives remains widely unexplored. Addressing this potential for fur- 
ther research, this paper examines how narratives influence the inter-urban mobility of policies and planning approaches. It intends to identify and characterize the main types of narratives involved within these processes and elaborates on how different local policy narratives relate to each other. These relations are understood as critical for the motion of policies between different spatial and functional contexts.

The argument put forth in this paper is based on an empirical study of local narratives on policies that support temporary uses of vacant sites and buildings in the German cities of Berlin and Stuttgart. These two cases represent different German federal states and almost contrary urban circumstances for policies on temporary use. Berlin, a city that, especially after its reunification, was characterized by an abundance of vacant spaces, is strongly linked to planners' initial appreciation of temporary use. By contrast, Stuttgart, one of southern Germany's economic powerhouses, is characterized by a high pressure real estate market and very few vacancies. Nonetheless, a public management agency for temporary use has been installed there to form part of its municipal business promotion. Based on interviews with experts from both cities and document analyses, this research characterizes dominant narratives on temporary use policies and elaborates on their relations.

The following is structured in six sections. Section 2 identifies the research gap by introducing the policy mobility debate with a special focus on literature that touches on narratives. It then extracts conceptual and methodological recommendations from political sciences' rich literature on policy narratives. Section 3 operationalizes these recommendations to a research design. It introduces and reasons the selection of case studies as well as the methods used. Section 4 presents the empirical data by characterising the main narratives on temporary use policies in Berlin and Stuttgart. The broader relevance of these empirical findings is discussed in Sect. 5, which characterizes the inner logic of the narratives, identifies different types of narratives and qualifies their relations. Finally, Sect. 6 offers conclusions and suggestions for future research.

\section{Conceptual reflections on narratives and policy mobilities}

\subsection{Narratives in the policy mobilities literature}

Inspired by the observation that exchanges of policy models between different cities have become significantly more dynamic over the past few decades, the research field "geographies of policy mobilities" explores the trans-local constitution of urban policies (McCann and Ward, 2011). This concept has proved useful for studies primarily on the international travel of diverse policies and planning approaches as demonstrated by recent publications from education (McKenzie et al., 2015) to smart city policies (Crivello, 2015). Policy mobility scholars emphasize their approach as social-constructivist and interdisciplinary (McCann and Ward, 2012; Künkel, 2015). It highlights "the fundamentally social - practical, interpersonal, institutionally embedded, yet fluid and processual - character of policy making in general and the social practices of comparison, education, emulation, imitation, and persuasion that characterize transfer of policies" (McCann and Ward, 2012:326).

Analogously, policy mobility rejects that policy models are copied as blueprints from one place to another. Instead, the post-structuralist approach conceives of policies as assemblages of, for instance, measures, experiences, ideas, discourses, and narratives. In this sense, assemblage can be understood as "an attempt to describe relationalities of composition - relationalities of near/far and social/material" (McFarlane, 2011:206). Assemblage allows for a theorisation of both the territorial and the relational influences on urban policy making (McCann and Ward, 2012). Assembling policies is understood as a pro-active and reflexive process, which is guided by interests, resources, power, and networks of actors involved. Pending on specific local problem statements, institutional settings and resources, stakeholders select suitable components of policies and form them to locally practicable models. In this context, McFarlane (2009:562) identifies a "labour of assembling and reassembling sociomaterial practices". Many works on policy mobility emphasized agency as critical and consider the interplay of a broad range of actors such as governmental representatives, private consultants, and NGOs (McCann and Ward, 2012). Peck and Theodore (2010:170) for example, stated that "consultants, advocates, evaluators, gurus, and critics" curate the "policy transfer business" by influencing the general perceptions of policies. Looking for "fast policy" solutions, local policy makers often trust these curators for clear, simplified information on the best policy solutions available (Peck and Theodore, 2015).

Moreover, policy mobility research places importance on the location of implementation and the communicative "channels" through which elements of policies are mobilized. Several works have pointed out how cities can turn into role models for distinctive policies. A classic example is Porto Alegre, which has become world-famous for participatory budgeting. Peck and Theodore (2015) reconstructed the development of the policy up to the point where it became "a pale imitation - some would say even parody of itself” (p. 151). While several problematic experiences hindered the potentially innovative approach from breaking through in Brazilian cities, an "elite consensus" established in international policy networks, advertised it as good governance and enabled it to circulate around the world.

Even further, authors identified examples of cities becoming emblematic of models that originated elsewhere. McCann and Ward (2014) for example, have demonstrated how business improvement districts spread from North America to the UK. The authors noted that even though the model originated in Canada, it is mostly associated with US 
cities as its most important promoters. Similarly, Temenos and McCann (2012) have argued that local policy making always has external effects. Examining the development of the sustainability policies of a Canadian tourist resort, they noted that "the local politics of policy mobility frequently involve the repeated dissemination of a creation (or importation) myth" (McCann, 2012:1397).

As this work and others have shown, presenting and styling policies seems to be critical for their mobilisation. Applying a different methodology, Gonzáles (2011) found similar tendencies. Her study on policy tourism showed how Barcelona and Bilbao evolved into models for urban regeneration, as hosting organisations collectively constructed narratives on regeneration processes in their cities: "The increasing external demand to tell a particular story and the relatively tight and formal nature of the host network have led to a consensual narrative" (Gonzáles, 2012:1413). This "orientalised" myth was reproduced through "fact-finding trips" (Gonzáles, 2012:1400), which policy tourists used to legitimize policies they often already employ in their home cities.

The critical role of narratives that Gonzáles refers to, has been discussed in other publications on policy mobilities, but only a few have considered the construction and misconstruing of narrative for the gain of local actors. Important groundwork in this sense and an inspiration for this paper has been provided by McCann (2008), who questioned why certain policies are negotiated as the normatively best solutions available. He argued that policy mobilities "are tied closely to powerful definitions of truth about best cities and best practices that profoundly shape policy" (McCann, 2008:899; cf. Foucault, 1981). Additionally, he suggested that "consultants, journalists, and activists, as well as politicians and government officials, are all experts of truth who create powerful narratives of cities' relationships to each other and to their populations and work to mobilize policies through these relational geographies" (McCann, 2008:890). "Products of expertise" (McCann, 2012:892) such as speeches, policy documents, maps, and lists of best practices are essential to construct and disseminate dominant narratives. To highlight the intentional moments of promoting "home made" urban policies, McCann (2013) proposed the notion of "policy boosterism". Here, policies are understood "as dynamic, relational constructions that emerge, not from specific policy-makers and places of invention but, rather, from the articulation of these people and places with audiences and places elsewhere" (McCann, 2012:6f.). This involves the reproduction of "narratives of 'success" " (McCann, 2012:10). Such narratives are mostly characterized by an inclusive rhetoric and emphasize potential benefits for other cities. They smooth over cracks between the specific and the general, thus making policies portable (cf. Rodgers, 2014:311).

In summary, the policy mobility literature highlights the social aspects of inter-local policy making. While, as the literature review has shown, diverse works have mentioned narratives on cities as critical, many questions relevant for theory and practice remain widely unexplored. Policy mobility research could hence benefit from in-depth studies on different types of narratives involved, as well as studies on the relations and interactions of varying narratives on policies. How do, for example, counter-positions of dominant "narratives of success" become established and effective in policy mobilities? Which differences and similarities do policy narratives in cities of policy "export" and cities of policy "import" indicate? It can be assumed that local particularities lead to different local narratives, but how do such local narratives relate to each other? Moreover, to date the policy mobility debate has not explicitly consulted the substantial body of literature on policy narratives within political science. It is time to consider the conceptual and methodological suggestions offered by this long-standing research tradition.

\subsection{Policy narratives in political sciences}

Deriving from literature studies, the narrative approach has increasingly gained value in social sciences, especially in political sciences. Polkinghorne (1995:5) generally defined narrative as "the type of discourse composition that draws together diverse events, happenings, and actions of human lives into thematically goal-directed processes". He added that narratives are often related to stories that describe "human attempts to progress to a solution, clarification, or an unravelling of an incomplete situation" (Polkinghorne, 2012:7).

As Jones et al. (2014:3) pointed out, "a considerable amount of scholarship was produced in the 1990s that examined the role of narrative in shaping public policy". These post-positivist, interpretative works developed theoretical ideas which were mostly not conducive to empirical research (e.g. Somers, 1994; Roe, 1994). Within this tradition, narratives are seen as guidelines for actions as well as essential parameters for the construction of experience and identity. They determine the acceptance of social practices and institutions (Fischer, 2003). Thus, narratives widely influence the political: They shape collective perceptions of policies and can also transport these perceptions from one place to another (cf. Boswell et al., 2011). Operationalized for this study of narratives of temporary use, the approach provides access to the social construction of causalities between perceived problems and perceived (policy) solutions in the cases studies of Berlin and Stuttgart examined here. The inter-local references of these narratives seem to be especially relevant as carriers of images, interpretations, and practical knowledge of temporary use policies.

According to Miller (2012:26), policy narratives "shape alliances and affect policy choices". To this end, narratives are not only used to promote, but also to impede policies. Those that impede are characterized as counter-narratives, which typically act in opposition to the predominant narrative. Ewick and Silbey (1995) provided some still valuable considerations of these "subversive stories". They noted that the interplay of narratives and counter-narratives can 
cause uncertain situations of policy formation and choice. This becomes particularly relevant in policy innovation processes (Fischer and Mandell, 2012). In a similar vein, Hajer (2005) stressed the significance of narratives when novel practices and policies are institutionalized. He emphasized that frequently repeated narratives dominate over others and become institutionalized in social practice. According to Miller (2012:17), "A legitimated policy narrative in turn licenses social action, warranting organizational practices such as those found in policy implementation and public administration". To this end, narratives can be understood as immanent to social regimes.

Miller (2012) elaborated on narrative production and identified three categories. The first comes "from historically embedded cultural practices", the second from "strategic manipulation", and the third "from chance encounters with fleeting symbolic imagery" (Miller, 2012:26). In the case of temporary use in Germany, all three categories should be considered. However, a degree of reflexivity regarding the production of narratives seems to be of particular importance. As implied in the policy mobility literature, especially those actors who seek to promote novel policies will strategically employ narratives that involve powerful symbols and stories of success to inspire collective actions (McCann, 2013). However, policy mobility scholars have so far neglected that counter-narratives might likewise be strategically created and spread to contradict narratives of success. Policy narratives on temporary use might - as "narratives of success" - stimulate and - as "counter-narratives of failure" - impede the mobilities of policies on temporary use.

Foucault (1981:56) emphasized the symbolic character of narratives by describing them as "things said once and preserved because it is suspected that behind them there is a secret or a treasure". As a result of their preservation, narratives are interpreted by different recipients and new narratives continuinously build on established ones. Even though narratives may not be built on "facts" alone (Czarniawska, 2010:73), they carry norms that become institutionalized. Ultimately, they are dispelled of controversy and are no longer contested. Roe (1994) added that "in some cases, we even know the policy narrative is factually inaccurate [...]. Nonetheless, we keep to the narrative anyway in absence of a better story and because, again, decisions have to be taken now" (p. 8). To this end, an analysis focused on narratives can shed light on the non-factual and non-technical aspects that shape perceptions in policy mobilities. Regarding the "discourse of truth", it is especially relevant to consider how perceptions of truth differ between local contexts.

Especially in recent years, research on policy narratives is experiencing a renaissance through the Narrative Policy Framework (NPF) (Shanahan et al., 2017; Jones et al., 2014). In order to "systematically study the variation of policy narratives" at the micro, meso, and macro level, the framework generally distinguishes between form and content of narratives (Jones et al., 2014:4). Narrative form consists of a com- bination of "setting, characters (heroes, victims and villains), plots, and a moral of the story (policy solution)" (Jones, 2012:5). The setting provides the specific context to a problem, which is usually characterized by a situation in space and time and its distinct institutions. It forms the stage for the narrative's characters. This category includes the producers of a problem, those who suffer from it, and those who seek to solve the problem. Characters can be individual humans, and also groups or abstract actors such as "the municipality". The plot typically consists of a beginning, middle, and end, connecting the characters and setting in various possible ways. Finally, the NPF labels a policy solution as the "moral of the story", but it also recognizes that there are narratives without classical solutions. Regarding the narrative content, as the concept's second overall category, NPF acknowledges that its understanding is relative to context. Likewise, the perception of the content can be structured in policy belief systems. Furthermore, the content of a narrative is often manipulated as part of a strategy. This includes, "the tactical portrayal and use of narrative elements to manipulate or otherwise control policy related processes, involvement, and outcomes" (Jones et al., 2012:9).

The NPF has been employed in various empirical fields such as climate change (Jones, 2014) or social innovations (Ney, 2014). It has not yet played a role in urban studies. For this paper, and in combination with conceptual elements from previous scholarly works on narratives, the NPF has been a useful groundwork for characterising different types of narratives on temporary use policies in Berlin and Stuttgart and for developing an adequate methodology.

\section{Research design and methodology}

While following policies and actors has become a typical approach to policy mobility studies (Wood, 2016), the research for this paper has been designed differently. To focus on the aforementioned variations of policy narratives that potentially influence policy mobility, it employed a case study methodology. This served first to profoundly characterize main local narratives on temporary use policies in different cities, and second, to identify the (inter-local) relations of these narratives. The cases of Berlin and Stuttgart represent major German cities with almost contrary structural circumstances. Especially after its reunification, Berlin was speckled with vacant sites and buildings that formed a predestined setting for temporary re-uses (SenStadt, 2007). For many years, the city was characterized by a low pressure real estate market and relatively low housing costs. It was known for its high number of creatives and artists, as well as for its tolerant atmosphere. Last but not least, many international publications describe Berlin as "the" important place for the development of temporary use policies and planning approaches (e.g. Patti and Polyak, 2015; Németh and Langhorst, 2013). Stuttgart, by contrast, ranks third among cities with the high- 
est housing costs in Germany (Empirica, 2016). Especially compared to Berlin, Stuttgart is a wealthy, densely used city characterized by very few vacancies. In Germany, Stuttgart and the region that surrounds it are known for their rather traditional and conservative mentality (Kunstbüro der Kunststiftung Baden Württemberg, 2013). Despite these structural differences, in both cities temporary use is addressed in some fashion by local policies. However, it can be expected that the ways temporary use have come to significance and thus the policy narratives on temporary use policies differ from each other.

Two methods are central for the identification and reconstruction of such local narratives. Literature on narrative analysis describes an interview as "a micro-site for the production of narratives, or just an opportunity to circulate them, where a researcher is allowed to partake of narratives previously produced" (Czarniawska, 2010). Thus, semistructured interviews have been conducted with a total of 26 central actors. These actors have been defined as central - or as the policy mobility literature suggests "experts of truth" (McCann, 2008) - as they have accompanied or influenced the formation of policies on temporary use in Berlin and/or Stuttgart and Germany in general. Interviewees were identified through prior explorative research of temporary use literature, primarily in German, and then via a snowball system. To consider the broad range of actors involved in policy mobility processes, the sample of interviewees consisted of planners, municipal actors, politicians, (former) managers of temporary-use businesses, and researchers. As the literature emphasized the importance of the reproduction of a "creation (or importation) myth" (Temenos and McCann, 2012:1397), interviewees were invited to speak on their perceptions of the ways temporary use has gained influence on planning and policies within the cities. They were asked about legitimations and causalities of the formation of temporary-use policies. Interviewees relayed their perceptions of problem statements, critical actors and their motivations, the potential of, and problems with the novel approach, as well as on external influences and inspirations from other places. They mostly shared experiences and interpretations in chronological order and produced narratives intuitively. In the next analytical step, these narratives were able to be condensed to central elements and compared, first regarding each case study individually, and then comprehensively. An orientation to the NPF, particularly to the categories of setting, characters, plot, and moral facilitated the comparison. At this point, similarities and references between narratives as well as counterpositions became evident.

Besides the importance of actors who shape and reproduce policy narratives, the literature emphasizes the relevance of "documents of truth" (McCann, 2008). Thus, the methodology's second major element was an analysis of documents on temporary use that have been published regarding both Berlin and Stuttgart in the past 25 years. The corpus of documents consisted of policy and municipal publications, sci- entific articles and books, online-presentations, and newspaper articles. It was particularly important to cover all documents published by the municipalities of Berlin and Stuttgart as they provide important sources of narratives. Their analysis allows for a reflection on municipal strategies of narrative production as they are implied in the NPF. Municipal publications included books, documented studies, guidelines, and web-texts. The analysis of documents helped to minimize any bias given by the selection of interview subjects. Moreover, documents complemented the narratives produced in interviews, especially as they treated policies, their discursive backgrounds, and related negotiations with a higher degree of reflection.

\section{Policy narratives on temporary use in Berlin and Stuttgart}

The interview and document analyses led to a set of interlinked narratives in Berlin and Stuttgart. It is striking that even interviewees with different professional backgrounds often shared similar narratives on temporary use policies in their cities. However, a comparison of local narratives between the two cases reveals major differences as detailed in this section with a focus on setting, characters, plot, and moral.

\subsection{Berlin's narratives on temporary use}

Two narratives, which refer to different periods of time as their setting, appear to be dominant in Berlin. The period from 1990 to the late 2000s is characterized by a "narrative of success" which builds around "creative practices of spatial appropriation and a golden age of temporary use". This narrative describes how formerly illegal occupations of vacant buildings and sites transformed into appreciated temporary uses and were seen as potentially useful for the creative city. Overall, this narrative supported temporary use policies and pushed further institutionalisation. Later stages were by contrast, characterized by a counter-narrative on the "tragedy of temporary use". This narrative highlights conflicts with the practice and related policies. It describes a turn in Berlin's real estate market, which hindered temporary use and, eventually, impeded the emergence of an alternative planning culture on temporary use.

\subsubsection{The narrative of success: "creative practices of spatial appropriation and a golden age of temporary use"}

When asked about the origins of Berlin's temporary use policies, most interviewees portrayed the fall of the Berlin Wall as the catalyst that made the city a unique place. They described the vast number of unused spaces and buildings, but also the almost anarchistic administrative conditions that allowed for deviant actions regarding these places. The time 
between the fall of the wall and Germany's reunification was characterized by political uncertainty. This setting provided a critical basis for the narrative. As for the characters, the emergence of squatters, who occupied vacant sites and buildings illegally, marked an important starting point. While some mentioned the ideological motivation of such characters, a larger number of interviewees attributed these "wild", early years to Berlin's artistic and cultural scene that discovered empty sites for parties, events, or exhibitions. Such initiatives created powerful images which interviewees recapitulated vividly: "There were people everywhere and in any place. There was a bar for two weeks, there was a gallery for three weeks, and that was crazy, you knew everything by word-of-mouth" (InterviewB1 urban planner).

The narrative's plot then develops a typical problem statement: in particular the document analysis suggested that during the late 1990s and early 2000s vacancies had mostly been discussed as highly problematic in discourse surrounding urban shrinkage in East German cities (e.g. Glock and Häußermann, 2004). Interviews contrasted this in Berlin by emphasising the vibrant temporary-use-scene that started to form during these years. Acting on the edges of squatting and cultural activity, these formerly illegal practices were increasingly reframed positively. "Berlin had a certain quality. That there were still places in which people could design very differently made us famous worldwide" (InterviewB5 temporary user). This shift from discussing vacancies as problematic to actually treating temporary use as potential for urban development turned out to be the crux of this dominant narrative. The fact that temporary use provided an unexpected solution, which originated outside the traditional constraints of planning, makes the narrative especially attractive and memorable.

Many interviewees stated that Berlin's spontaneous, temporary developments inspired planners, who then developed a new attitude towards such uses. These important characters of the narrative lauded temporary use as a form of direct participation and promoted the approach as a means of achieving a creative and citizen-oriented planning culture (Bader and Mayer, 2005; Studio Urban Catalyst, 2003). Such charismatic ascriptions of potential were reproduced and amplified in several of the Berlin Senate's publications on creative urbanism. One such book, Urban Pioneers (SenStadt, 2007), was for many interviewees an important "document of truth" (McCann, 2008), which established the image of temporary use as a locational factor for the creative city. It was the wellrecognized product of collaboration between two important characters in the narrative: Berlin's Senate Department for Urban Development and alternative urban planners, who initially promoted temporary use policies.

For many interviewees the end of this narrative's plot and its moral were marked by the formation of versatile urban policies to support temporary use in Berlin. Several mentioned, for instance, the foundation of the "Agency for Temporary Use" (German: Zwischennutzungsagentur). De- riving from the Berlin based initiative, the term is now used throughout Germany for the entire type of offices that facilitate temporary use. The large-scale redevelopment project of Berlin's famous inner-city airport Tempelhof has been mentioned as a final indicator for the substantial institutionalisation of temporary use within Berlin's planning culture. After the airport's closing, its airfield was opened as a public park in 2010 and three sections have been designated for temporary use, such as community gardens. Berlin's Senate has communicated the project as an innovative form of participation and it has been positively reviewed as such in external publications (e.g. Bauwelt, 2011). Likewise, many interview subjects perceived the project as the city's final and only real attempt to support temporary use, as emphasized in the following narrative.

\subsubsection{The counter-narrative: "the tragedy of temporary use"}

In more recent years, a counter-narrative suggests that temporary use has lost its often praised innovative aura and that it has even taken on a negative connotation. In many interviews it is described as having gained influence since 2007, when the city's real estate market experienced a drastic shift. "Between 2007 and 2012 practically all vacant sites in Berlin were sold at least once. [...] That does not mean that all projects are gone, but it means that the conditions of the 1990s have increasingly disappeared" (InterviewB4 municipal official). This significant change of setting introduced the problems that this narrative's plot is built around. Many popular temporary use projects could not receive contract extensions, which led to open conflict between land owners and temporary businesses that had to leave sites. Moreover, the narrative clearly articulates the tension between the temporary use scene and the city: interviewees from temporary projects which could not concede longer term contracts complained about insufficient support from the municipality. At the same time, documents show that even activists from the left wing started to criticize remaining projects as "motors of gentrification" (Girgert, 2013). Other commentators recognized how temporary users became victims of their own success as the more popular projects triggered an augmentation in the value of real estate (Kil, 2014). "In Berlin, we are insulted as gentrifiers, but, in fact, we are the first victims of gentrification. Of course, our activities make places more interesting", stated a former temporary user (InterviewB5 temporary user).

The change in Berlin's real estate market was perceived as "tragic" by several interviewees as it became especially effective just when temporary use was gaining a more general appreciation by municipal actors and the public. "There were many more people who said: 'we need such approaches' and so on. In fact, they became broadly accepted in the moment the projects came into crisis" (InterviewB4 municipal official). In the face of rising housing costs, the creation of poli- 
cies to secure affordable dwellings gained importance for Berlin's Senate. Consequently, the development of a stronger institutional framework for temporary use suddenly appeared less critical. Almost theatrically, the tragic course of this narrative constitutes its attraction and the momentum it gained. Even further, it drastically undermines the moral of the narrative of success and suggests that Berlin's Senate never consistently institutionalized temporary use policies and acted rather passively:

- "It was the municipality's honourable task to be tolerant, and not to intervene. But there was no strategic contribution." (InterviewB3 urban researcher);

- "[The book Urban Pioneers] was so to say the first time that our House [the Berlin Senate] treated this systematically and - well - that we said: 'Interesting development, we would like to document this and so on.' [...] It didn't have consequences in the sense that institutions were set up. [...] Real institutions for temporary uses, as in other cities, have never existed in Berlin" (InterviewB4 municipal official).

Again, the book Urban Pioneers plays an important role in this narrative. However, the turning point it marks in this case did not lead to more profound institutionalisation. By contrast, it is understood as the moment in which the development started to lose momentum in Berlin. Interviewees described an alternative planning culture that developed within certain professional circles. However, apart from projectrelated funding and the aforementioned flagship project of Tempelhof Airport, this culture never reached the municipal institutions. Documents and interviews revealed the "Agency for Temporary Use", a character from the narrative of success, as a fully private initiative, which has never been institutionally funded on a long-term basis as in other cities and has only received short-term support from one Berlin district. Still, politicians and the city's marketing agency have framed temporary use as a unique feature of Berlin's cityscape (cf. Colomb, 2011). "In a certain speech, the senator said 'our agencies for temporary use'. Just as a Frankish mayor would say 'our sausages', even though he has never spent a public cent on sausages. It is simply a regional speciality" (Interview B6 urban planner). Symbols of success - be they agencies or books - are essential pillars to these narratives and they are strategically produced. After Urban Pioneers garnered international attention, Berlin's Senate published four additional books, which refer to the city's alternative planning culture in a similar vein.

Interviews and documents suggest that the issue of temporary use has increasingly lost significance in Berlin. A strong element of this plot is that its former protagonists in particular, have abandoned the approach. For instance, important characters such as planning offices that had specialized in consultancy regarding temporary use have since tended to diversify their profiles to include longer term developments.
This has even affected the semantic level of labelling the approach. Documents suggest that many Berlin actors in recent years have avoided the term Zwischennutzung (temporary use) when referring to their work. Likewise, Berlin's municipality seems to have adapted to the counter-narrative, as the term is not used in its more recent publications any longer (e.g. Feireiss and Hamm, 2015).

\subsection{Urban policies and narratives on temporary use in Stuttgart}

The approach of temporary use arrived significantly later in Stuttgart than in Berlin. However in Stuttgart, it has been institutionalized in a stronger way, especially at the formal level of public policies (Landeshauptstadt Stuttgart, 2013). A principle instrument of this is Stuttgart's "Management for Vacancies and Temporary Use" established by the municipality in 2012 (Leerstands- und Zwischennutzungsmanagement (LZM)). This agency primarily mediates between landowners and temporary businesses. A public manager serves as the central municipal contact person and consultant for those who want to realize temporary use. The LZM forms part of Stuttgart's local business promotion, which is immediately headed by the city's mayor. It runs a website and published a Guideline for Creative Temporary Users (Leitfaden für kreative Zwischennutzer) with information for different stakeholders (Landeshauptstadt Stuttgart, 2014). As a second policy element, the LMZ heads an integrated municipal project group, constituted by representatives of the departments for culture, public order, real estate management and housing, as well as construction legislation. The committee meets frequently to discuss recent projects and challenges. Besides the policy elements that directly address temporary use, Stuttgart's municipality supports urban community gardens in an exceptional way in Germany, as it has contracted a public manager for urban gardening. Publicly supported projects are often carried out as temporary uses of vacant lands and they combine gardening with other cultural activities.

As a late adopter, the activities of Stuttgart's municipality can be characterized by a much higher degree of reflexivity. In the introduction of Urban Pioneers, a political representative of Berlin's Senate stated that, "Berlin is a laboratory for businesses of temporary uses. Berlin has space. Numerous disused, un-built, and unplanned spaces, some of them very large, are a physical reflection of the city's history and structural upheaval" (SenStadt, 2007:17). By contrast, the wording in Stuttgart's guidelines for creative, temporary users is significantly different, even though it clearly embodies elements of Berlin's narrative of success: "especially in prosperous regions, a consequent management for temporary uses is an important element to conserve creative and inspiring spaces and can serve as a suitable element of urban development projects" (Landeshauptstadt Stuttgart, 2014:1). Labelling this as "management" already employs the semantics 
of business promotion, which are also reflected in the content of work: "It was a basic idea to support Stuttgart as an economically attractive location" (InterviewS1 municipal official). The LZM specifically aims at providing temporary office space to creatives. Another municipal interviewee mentioned the aspect of neighbourhood development: "such actors are useful as they prepare the land to a certain end, so that mixed-use neighbourhoods can develop and that a certain quality can be created" (InterviewS2 municipal official).

Statements like these provide the immediate background for the profound municipal support of temporary use. However, they do not explain why temporary use was chosen over a multitude of other ways to support creativity oriented urban development in a city that is not at all characterized by an abundance of vacancies. Especially from a policy mobility perspective, one must ask how the city came to this selection of policy and why the municipal actors considered temporary use as the "true" solution. To answer this, an exploration of main local policy narratives on temporary use appears useful.

The rather limited number of documents on temporary use in Stuttgart offered little insight into policy narratives, but they helped to complement narratives that interviewees shared on the backgrounds of local policies. The first narrative describes how the approach was developed intrinsically in response to a "lack of spaces for alternative culture" in Stuttgart. The second, relational narrative highlights the external influences of "Berlin, where anything seems possible". Unlike in Berlin, the two main narratives in Stuttgart do not refer to different temporal settings, nor can one be characterized as a counter narrative to a dominant one.

\subsubsection{The narrative of innovation: "a lack of spaces for alternative culture"}

This narrative again begins with Stuttgart's spatial context as the setting for the central problem of the narrative's plot: Many interviewees mentioned the tense real estate market as a significant factor that hinders an alternative urban culture from flourishing, and thus limits this perceived quality of life to certain parts of the population. Due to the city's topography, many activities are concentrated in its centre, which causes high rental prices and economic stress. Furthermore, an aspect of the local mentality was mentioned: real estate owners were described as careful regarding the rental of their properties on a temporary basis. "We simply lack these buildings. Usually, sites are developed quite quickly. This is, on the one hand, absolutely positive, as the urban image is not neglected. On the other hand, it eliminates the spaces for such possibilities", stated one interviewee (InterviewS1 municipal official). Another one added that: "the spatial cake here has already been distributed for years [...] only big companies with their international power can afford sites" (InterviewS3 urban planner). Stuttgart is seen as the region's traditional cultural hotspot as the city hosts an opera and a theatre among other things. However, as a quantitative study under- lines, younger citizens in particular perceive a lack of alternative culture (Kunstbüro der Kunststiftung Baden Württemberg, 2013).

Interviewees from outside the municipality referred to Stuttgart's own local history of alternative cultural projects, many of which have disappeared. It is striking how some projects have significant influence on the local narratives on temporary use. One extant example is the Wagenhallen, a former train garage, which has been divided into a concert hall and artist spaces. The Wagenhallen was made possible as a side effect of a large scale rail-infrastructure project called Stuttgart21. This project has created several vacancies throughout the city into which actors have been granted temporary access. In contrast to the success of Wagenhallen, many other temporary projects have lost their sites.

One less successful example was the project $H 7$, initially made possible, but ultimately also cancelled because of Stuttgart21. The eviction of $H 7$ caused protests and was also accompanied by critical media reactions (e.g. Manz, 2011). $H 7$ 's eviction was depicted as a symbol for the lack of alternative spaces in Stuttgart and the municipality's neglect of citizens' needs. Interviews and documents suggested that the protests around Stuttgart 21 are central to the narrative's plot as they put pressure on local politicians and have left an ethos of self-empowerment among the citizens.

Ultimately, Stuttgart's formation of the LMZ unit is treated as the narrative's moral. Regarding the narrative strategy, it is striking how the municipal actors intentionally coin special terminology to distinguish Stuttgart's approach from those in other cities. Interviewees emphasized that the city went its own and exceptional way. The fact that the city of Stuttgart brands the LZM as unique and as Germany's first public agency for temporary use illustrates this (InterviewS6 municipal official).

\subsubsection{The relational narrative: "anything is possible in wild Berlin"}

Besides the references to projects and developments in Stuttgart, another strong narrative is built around the cityscape of temporary use and respective policies in Berlin. Within this relational narrative, Berlin is said to provide the ideal urban setting for the stimulation of an alternative urban culture. In this understanding, Berlin offers just those urban features that Stuttgart citizens long for in their own city.

Interviewees from Stuttgart with very different backgrounds referenced the setting provided by Berlin in similar ways. An interviewed manager of a temporary project described how he was inspired by projects and images he saw during a visit: "In Berlin, I perceived the RAW temple [temporary use project] and such things, or some clubs in the second basement of some houses. Such spaces open up there all the time. [...] If you play your music a bit louder here, the police will arrive immediately. Yonder, it is completely different. What a paradise, I thought" (InterviewS3 temporary 
user). This quote demonstrates how narrative can arise from short visits, even when they are not intended for learning policy (cf. Gonzáles, 2011).

With regard to the aforementioned 'policy importation myth' (Temenos and McCann, 2012), most interviewees perceived Berlin as temporary uses' place of origin. One interview subject added that the term Zwischennutzung refers to "its own genre" of spatial usage and planning specific to Berlin (InterviewS3 temporary user). Others described Stuttgart's creative neighbourhoods as "Berlin-like". The document analysis confirmed these tendencies. One study concludes, for example, that extraordinary high numbers of young citizens from the Stuttgart region - especially from the creative sector - decide to move to Berlin after graduation (Kunstbüro der Kunststiftung Baden-Württemberg, 2013:29). This underlines the efficacy of the image of Berlin. Moreover, several interview subjects described how the reference to Berlin is employed as a pressuring argument by activists when claiming for supportive policies and a Berlinlike urbanism:

They all appeared with sashes saying: 'We don't want to go to Berlin'. Well, if you shorten [expenses on culture] and make things more expensive, then we all just leave and what happens then? Then, you will only import art and organize exhibitions, but you won't produce it yourself (InterviewS4 urban planner).

These references to Berlin were not only made by the bottom-up actors, but the interviewees from the municipality also included them within their narratives. On the one hand, municipal actors perceive pressure to keep young citizens from leaving the city for Berlin. On the other hand, they mention Berlin as a concrete inspiration for active municipal support of temporary use in their own city:

- "I think that not only in Stuttgart, but in many cities in Germany, certain actors look to Berlin. The matter of temporary use is discussed as if it was unproblematic in Berlin [...] Apparently, these things are treated quite dynamically there. And somehow you experience this yourself, when you are there. You come back and you say: 'Wow, there it works much better and why doesn't it work here"' (InterviewS1 municipal official);

- "A lot comes from Berlin [... Certainly, it also depends on how loudly you beat the drums" (InterviewS5 municipal official).

It is striking how interview subjects from Stuttgart referred to an innovation narrative, which Berlin interviewees similarly produced. However - and this makes all the difference - they referred to a period in the early 2000s, when circles of alternative planners started to develop appreciation for temporary use. The unusual setting of a "golden age of temporary use" and the core message of turning problematic vacant sites into hotspots of the creative city has emanated a fascination far beyond the city. The myth of Berlin seems to be highly effective in Stuttgart: As a localized expression of a perceived collective need, it influenced the formation of policies. By contrast, Stuttgart's relational narrative to Berlin does not at all reflect Berlin's counter-narrative, which is built around the conflicts related to the approach and the disappearance of stimulating urban conditions. Apparently, actors in cities of policy import are highly selective in their perceptions of narratives and do not necessarily seek facts.

\section{Discussion: relational narratives and the motion of urban policies}

Similar to policy mobility scholars' assumptions regarding policy assemblages, Stuttgart's set of policy narratives on temporary use is composed of territorial and relational influences. Moreover, by concentrating on policy narratives in different cities, this study has shed light on formerly neglected aspects of policy mobility, of which three will be discussed below.

First, while the narrative term has been used rather contextually, if not superficially, in the existent policy mobility literature, this study has helped to develop a deeper understanding of the inner logic of such policy narratives that show their effect on policies in motion. It has shown that different narratives consist of similar (if not the same) elements which are composed differently to communicate a powerful central message. Orienting to categories of the Narrative Policy Framework, typical formal elements of dominant narratives in Berlin and Stuttgart could be identified and structured by setting, character, plot, and moral. Depending on context and intention they are (re-)arranged differently and, at times discrepantly. Yet these formal elements demonstrate the simplicity of this still influential aspect of communication. Furthermore, narratives in Berlin and Stuttgart are built around powerful plot elements, which often involve turning points. Gonzáles (2011) attested that the planner community has a fascination for stories about cities that "emerge like a phoenix after crisis" (p. 1397). It is exactly this type of plotmoral element that can be found in Berlin's "narrative of success" and which evolved into a foundation myth for a whole new generation of planners. The enormous number of vacant houses and sites - once perceived as evidence of urban crisis and planners' helplessness - were now able to be turned into symbols of cultural prosperity and more democratic urban planning. Also the main characters of this narrative (squatters, artists, etc.) are unexpected within the context of urban planning: Formerly disapproved occupations of space were suddenly in league with the traditional institutions that many associate with control and restriction. Last but not least, the setting of reunified Berlin is charged with a wild and ruinous, yet vibrant charm. As stated by Jones and McBeth (2010), these "stories that change the way we view the world do violence to the norm, breach banality, and rend our expec- 
tations" (p. 343). In a similar vein, another Berlin counternarrative stylizes the tragedy of the temporary use approach in an almost theatrical fashion. Here, the once inspiring setting of the city is normalized and becomes dominated by the market's invincible force. At this drama's climax, the former protagonists change sides, and those activists and planners who once promoted approaches on temporary use turn into critics.

Secondly, this analysis has suggested that various local narratives determine the motion of policies. It is thus important to consider not just one powerful narrative, but rather a set of different, partly competing local narratives as relevant for policy mobilities. In Berlin and Stuttgart these local narratives do not stand apart from one another, rather they are interlinked and often depend on each other. "Local" addresses the fact that plots mostly arise from the spatio-temporal setting of the city. This involves, for example, particularities of the city's history, cultural predispositions and local actors. As the "the narrative approach focuses on symbolic meanings, connotations, and associations" (Miller, 2012:3), local projects and events appear as symbols of success or as symbols of failure. Often they mark turning points, as the publication of Urban Pioneers did in Berlin's narratives or the infrastructure project Stuttgart21 did in Stuttgart. Moreover, local narratives seem to rank in hierarchies, which influence perceptions of truth regarding local problems and policies as solutions. Hierarchies of competing narratives change with time until a new narrative completely dominates the former. In Berlin the counter-narrative has become prevalent in recent years. Analogously, semantics have changed and the term Zwischennutzung has increasingly disappeared. Most relevant for policy mobility research, the examined cases show how local narratives are linked to the supra-local and unfold an efficacy in other cities. Even though the comparison has revealed vast differences of policies implemented on temporary use in both cities, Stuttgart actors make significant references to Berlin.

Third and finally, this research suggests that policies become particularly mobile when different local narratives strongly correspond with each other. The case study methodology presented in this paper has allowed for a relational analysis of narratives in "cities of export" (represented by Berlin) and "cities of import" (represented by Stuttgart) as two typical categories in the policy mobility literature. For both sides, the narratively constructed origins of temporary use policies could be identified. Miller (2012) postulated that narratives can originate "from historically embedded cultural practices", "strategic manipulation" and "from chance encounters with fleeting symbolic imagery" (p. 26). In both cities the first category can be found in one narrative, which refers to an intrinsic history of alternative urban planning. Local projects, events, and influential actors are included as a policy's local anchor points. These serve to justify different steps of institutionalisation and create agency regarding temporary use policies. As also addressed by McCann's (2013) proposal on "policy boosterism" and NPF's category strategy (Jones et al., 2014), the promotion of narratives of success has played a role on the export-side. In the case of Berlin, documents especially suggested that the municipality incorporated and circulated a policy narrative that had been inspired by grass roots actors and alternative planners. Berlin's municipality's special efforts to stage ornamental flagship projects such as Tempelhof field have not gone unnoticed. At several points, municipal representatives also construed the local temporary use scene as an outcome of policies, even though - especially in comparison to Stuttgart - the institutionalized support for temporary use remained rather low.

As for the import side, one Stuttgart narrative expresses a collective longing for absent urban qualities and involves symbols of loss such as disappeared temporary use projects. Adding to the weight of these symbols, a relational narrative describes Berlin as the utopia that provides just the urban qualities Stuttgart is lacking. To this end, both the solution, in the form of temporary use policies, and the local problem have already been defined with strong external references. The relational narrative also helps ease uncertainties that are typical for the introduction of radically new policies as it suggests the approach has already been "successfully" implemented elsewhere. It is striking, that actors on the import-side widely ignore Berlin's counter narrative on struggles with temporary use. The strong image produced in the narrative of success seems to outshine the fact that institutionalized, long-term policies on temporary use have never existed in Berlin. This underpins that policy narratives do not necessarily rely on what are collectively acknowledged as facts. As prominently discussed in the nonacademic post-truth-debate, they involve nebulous ideas, personal beliefs, and emotions. Narratives on role model places reveal their potential especially when "strategic manipulation" on the export-side meets "fleeting encounters" on the import-side (cf. Miller, 2012). This fundamental simplification can streamline the negotiations between different positions during processes of policy making. However, when conflicts are ignored, they may be imported through narratives.

\section{Conclusions}

This paper has researched how narratives on policies, cities, and projects influence the territorial and relational constitution of urban policies. While the existent policy mobility literature has often touched implicitly on the relevance of narratives, the results of this paper encourage more profound considerations of narratives as structural foundations for communication and knowledge sharing in this field. Narrative approaches bear unused conceptual and methodological opportunities for researching the non-technical and emotional aspects of trans-local policy making. Focusing on imagination and association, narratives are particularly valuable to recon- 
structing how collective perceptions of "true" policy solutions are shaped, and also to understanding how perceptions of urban problems are constructed relationally.

Empirically this paper, firstly, characterized the main narratives on policies that support temporary use of vacant lands and buildings in the German cities of Berlin and Stuttgart and secondly, identified and qualified the relations of these narratives. It has argued that these relations are especially critical for the motion of policies. In both cases, actors tended to be collectively biased by figurative, easily reproducible narratives that transport interpretations of policies' backgrounds, as well as by perceptions of success or failure. Narratives create causalities between urban images and desirable features of cities, and specific policies. The fact that policies implemented in the examined case study cities are very different suggests that a selected narrative became mobile and "travelled" to other cities rather than the actual policies. Likewise and potentially controversially, this paper has found that influential narratives can tell very different stories about the same phenomenon. Narratives' typical elements such as the setting and characters are often identical, but (re-)arranged and interpreted differently. It is striking that the sources of information are often not questioned by actors and, thus, a "touch of post-truth" seems to be acceptable or even necessary for policy models to thrive inter-locally.

It deserves to be emphasized that narrative does not have to be an undefined category for future policy mobility research. Even though this paper has characterized narratives as sensitive to local contexts, it has identified different overall types of narratives that frequently occur. The first type, "narratives of success", advocates for and justifies the development of novel policies. As this type of narrative reproduces those aspects of policies that have been perceived positively, it stimulates the policies' mobilisation. The second type, "counter narratives", usually undermines the narrative of success. Counter narratives are built around conflicts with policies and, thus, impede the mobilities of policies. The third type, "relational narratives", creates references to other spatial contexts and narratives already in place within these contexts. For future research, the NPF is especially promising as it allows for a differentiated treatment of narrative's form and content as well as the examination of different scales on which narratives become effective. Debates on "policy boosterism" in particular, could benefit from the NPF's profound consideration of strategic application of narratives and belief systems. Ultimately, this paper is limited due to its focus on case studies from one national system. Thus, there is a need for empirical case studies from different national contexts. Such research could also apply a "following the narratives" approach in order to understand how narratives on urban policies evolve through time and space thus affecting the making of urban policies.
Data availability. This article is based on the research project "Innovations in Spatial Planning" (InnoPlan) funded by the Deutsche Forschungsgemeinschaft (DFG) (grant number $\mathrm{CH}$ 864/3-1). It was conducted at the Leibniz Institute for Research on Society and Space (IRS) and Stuttgart University from October 2013 until April 2016. For data protection reasons transcriptions of interviews that formed part of the methodology are not publicly available.

Competing interests. The author declares that he has no conflict of interest.

Acknowledgements. I would like to thank my colleagues involved with the research project InnoPlan (Gabriela Christmann, Oliver Ibert, Johann Jessen, Uwe-Jens Walther, Franz Füg, Oliver Koczy and Daniela Zupan) as well as Ilse Helbrecht for our many fruitful discussions. Also I would like to express my gratitude to the editor and the two anonymous reviewers for their constructive comments and thoughts.

Edited by: Myriam Houssay-Holzschuc

Reviewed by: two anonymous referees

\section{References}

Bader, A. and Mayer, C.: Kolorado Neustadt. Aktive Diversifizierung und situative Praxis im Stadtumbau [Kolorado Neustadt. Active diversification and situative practice in urban regeration], Informationen zur Raumentwicklung, 3/4, 179-189, 2005.

Bauwelt: Berlin-Tempelhof: the big empty. Special Issue on the Berlin project "Tempelhofer Freiheit", Bauwelt, 36/2011.

Boswell, C., Geddes, A., and Scholten, P.: The role of narratives in migration policy making: a research framework, The British Journal of Politics and International Relations, 13, 1-11, https://doi.org/10.1111/j.1467-856X.2010.00435.x, 2011.

Colomb, C.: Staging the new Berlin. Place marketing and the politics of urban reinvention post-1989, London, Routledge, 2011.

Crivello, S.: Urban policy mobilities: the case of Turin as a smart city, Eur. Plan. Stud., 23, 909-921, https://doi.org/10.1080/09654313.2014.891568, 2015.

Czarniawska, B.: The uses of narratology in social and policy studies, Critical Policy Studies, 4, 58-76, https://doi.org/10.1080/19460171003715002, 2010.

Empirica: Empirica Immobilienpreis-Index IV/15, available at: http://www.empirica-institut.de/fileadmin/Redaktion/ Publikationen_Referenzen/PDFs/Immobilienpreisindex_ Q42015.pdf (last access: 9 March 2018), 2016.

Ewick, P. and Silbey, P.: Subversive stories and hegemonic tales. Toward a sociology of narrative, Law Soc. Rev., 29, 197-226, https://doi.org/10.2307/3054010, 1995.

Feireiss, K. and Hamm, O. G. (in co-operation with the Senate Department for Urban Development and the Environment, Berlin) (Eds.): Transforming cities. Urban interventions in public space, Berlin, Jovis, 2015.

Fischer, F.: Reframing public policy. Discursive politics and deliberative practices, New York, Oxford University Press, 2003. 
Fischer, F. and Mandell, A.: Transformative learning in planning and policy deliberation, in: Probing social meaning and tacit assumptions, edited by: Fischer, F. and Gottweiss, H., The argumentative turn revisited. Public policy as communicative practice, Durham and London, The University Press, 343-370, 2012.

Foucault, M.: The order of discourse, in: Untying the Text: a Poststructuralist Reader, edited by: Young, R., Boston, Routledge and Kegan Paul, 48-78, 1981.

Girgert, W.: Zwischennutzung als Aufwertungsmotor [Temporary use as a motor of gentrification], german-architects, eMagazin, available at: http://www.germanarchitects.com/pages/ hauptbeitrag/2213_gentrifizierung (last access: 9 March 2018), 2013.

Glock, B. and Häußermann, H.: New trends in urban development and public policy in eastern Germany: dealing with the vacant housing problem at the local level, Int. J. Urban Regional, 28, 919-929, https://doi.org/10.1111/j.0309-1317.2004.00560.x, 2004.

Gonzáles, S.: Bilbao and Barcelona "in motion". How urban regeneration "models" travel and mutate in the global flows of policy tourism, Urban Stud., 48, 1397-1418, https://doi.org/10.1177/0042098010374510, 2011.

Hajer, M. A.: Coalitions, practices and meaning in environmental politics: from acid rain to BSE, in: Discourse theory in european politics: identity, policy and governace, edited by: Howarth, D. and Torfing, J., Hampshire, Palgrave Macmillan, 297-315, 2005.

Healey, P.: The universal and the contingent: some reflections on the transnational flow of planning ideas and practices, Plan. Theor., 11, 188-207, https://doi.org/10.1177/1473095211419333, 2011.

Healey, P.: Circuits of knowledge and techniques. The transnational flow of planning ideas and practices, Int. J. Urban Regional, 37.5, 1510-1526, https://doi.org/10.1111/1468-2427.12044, 2013.

Jones, M. D.: Communication climate change: Are stories better than "just the facts"?, Policy Stud. J., 42, 644-673, https://doi.org/10.1111/psj.12072, 2014.

Jones, M. D. and McBeth, M. K.: A narrative policy framework: clear enough to be wrong?, Policy Stud. J., 38, 329-353, https://doi.org/10.1111/j.1541-0072.2010.00364.x, 2010.

Jones, M. D., McBeth, M. K., and Shanahan, E. A.: Introducing the Narrative Policy Framework, in: The Science of Stories. Applications of the Narrative Framework in Public Policy Analysis., edited by: Jones, M. D., McBeth, M. K., Shanahan, E. A., New York, Palgrave Macmillan, 1-25, 2014.

Kil, W.: Bleiberecht zum Höchstgebot [Right of residence for the highest bid], Informationen zur Raumentwicklung, 2.2014, 123127, 2014.

Künkel, J.: Urban policy mobilities versus policy transfer. Potenziale für die Analyse der Neuordnung des Städtischen [Potentials for analysing the re-ordering of the urban], Sub \urban, 3, 7-24, 2015.

Kunstbüro der Kunststiftung Baden-Württemberg: BadenWürttemberg: Ein Ort für junge Künstler? [Baden-Württemberg: a place for young artists?], Stuttgart, Kunststiftung BadenWürttemberg GmbH, 2013.

Landeshauptstadt Stuttgart - Wirtschaftsförderung: Leerstands- und Zwischennutzungsmanagement der Landeshauptstadt Stuttgart, [Vacancy and temporary use management of the captial Stuttgart], Presentation at "Forum deutscher Wirtschaftsförderer”, Berlin, 14-15 November 2017, 2013.
Landeshauptstadt Stuttgart - Wirtschaftsförderung: Leitfaden für kreative Zwischennutzer. Leerstands- und Zwischennutzungsmanagement [Guideline for creative temporary users. Vacancy and Temporary Use Management], Stuttgart, Landeshauptstadt Stuttgart, 2014.

Manz, E.-M.: Das H7 wird vorzeitig geräumt [The H7 will be evicted ahead of schedule], Stuttgarter Zeitung, 11 December 2011.

McCann, E.: Expertise, truth, and urban policy mobilities: global circuits of knowledge in the development of Vancouver, Canada's "four pillar" drug strategy, Environ. Plann. A, 40, 885-904, https://doi.org/10.1068/a38456, 2008.

McCann, E.: Policy boosterism, policy mobilities, and the extrospective city, Urban Geogr., 34, 5-29, https://doi.org/10.1080/02723638.2013.778627, 2013.

McCann, E. and Ward, K. (Eds.): Mobile urbanism. Cities and policy making in the global age, Minneapolis, London, University of Minnesota Press, 2011.

McCann, E. and Ward, K.: Policy assemblages, mobilities and mutations: Toward a multidisciplinary conversation, Polit. Stud. Rev., 10, 325-332, https://doi.org/10.1111/j.14789302.2012.00276.x, 2012.

McCann, E. and Ward, K.: Exploring urban policy mobilities: the case of business improvement districts, Sociologica, 1/2014, 120, https://doi.org/10.2383/77048, 2014.

McFarlane, C.: Translocal assemblages: space, power and social movements, Geoforum, 40, 561-567, https://doi.org/10.1016/j.geoforum.2009.05.003, 2009.

McFarlane, C.: Assemblage and critical urbanism, City, 15, 204224, https://doi.org/10.1080/13604813.2011.568715, 2011.

McKenzie, M., Bieler, A., and McNeil, R.: Education policy mobility: reimagining sustaiability in neoliberal times, Environ. Educ. Res., 21, 319-337, https://doi.org/10.1080/13504622.2014.993934, 2015.

Miller, H. T.: Governing Narratives. Symbolic Politics and Policy Change, Tuscaloosa, The University of Alabama Press, 2012.

Németh, J. and Langhorst, J.: Rethinking urban transformation: Temporary use for vacant land, Cities, 40, 143-143, https://doi.org/10.1016/j.cities.2013.04.007, 2013.

Ney, S.: The governance of social innovation: connecting meso and macro level of analysis, in: The science of stories. applications of the narrative framework in public policy analysis, edited by: Jones, M. D., McBeth, M. K., and Shanahan, E. A., New York, Palgrave Macmillan, 208-234, 2014.

Oxford Dictionary: Definition of post-truth in English, available at: https://en.oxforddictionaries.com/definition/post-truth (last access: 12 October 2017), 2016.

Patti, D. and Polyak, L.: From practice to policy: frameworks for temporary use, Urban Research and Practice, 8, 122-134, https://doi.org/10.1080/17535069.2015.1011422, 2015.

Peck, J. and Theodore, N.: Mobilizing policy: Models, methods, and mutations, Geoforum, 41, 169-174, https://doi.org/10.1016/j.geoforum.2010.01.002, 2010.

Peck, J. and Theodore, N.: Fast policy: experimental statecraft at the thresholds of neoliberalism, Minneapolis, London, University of Minnesota Press, 2015.

Polkinghorne, D. E.: Narrative configuration in qualitative analysis, Journal of Qualitative Studies in Education, 8, 5-23, https://doi.org/10.1080/0951839950080103, 1995. 
Rodgers, D. T.: Bearing tales: networks and narratives in social policy transfer, Journal of Gobal History, 9, 301-313, https://doi.org/10.1017/S1740022814000084, 2014.

Roe, E.: Narrative policy analysis: Theory and practice, Durham, NC, Duke University Press, 1994.

SenStadt - Senatsverwaltung für Stadtentwicklung Berlin: Urban Pioneers. Stadtentwicklung durch Zwischennutzung [Urban Pioneers. Urban development with temporary use], Berlin, jovis, 2007.

Shanahan, E., Jones, M. D., McBeth, M. K., and Radaelli, C. M.: The narrative policy framework, in: Theories of the Policy Process, edited by: Weible, C. and Sabatier, P., 4th edition, Boulder, Westview Press, 173-213, 2017.

Somers, M. R.: The narrative constitution of identity: a relational and network approach, Theor. Soc., 23, 605-649, https://doi.org/10.1007/BF00992905, 1994.
Studio Urban Catalyst: Urban Catalysts. Strategies for temporary uses - potential for development of urban residual areas in European metropolises, available at: http://www.templace.com/ think-pool/attach/download/1_UC_finalR_synthesis007b.pdf (last access: 9 March 2018), 2003.

Temenos, C. and McCann, E.: The local politics of policy mobility: Learning, persuasion, and the production of a municipal sustainability fix, Environ. Plann. A, 44, 1389-1406, https://doi.org/10.1068/a44314, 2012.

Wood, A.: Tracing policy movements: Methods for studying learning and policy circulation, Environ. Plann. A, 48, 391-406, https://doi.org/10.1177/0308518X15605329, 2016. 